\section{$\underset{\substack{\text { hommes } \\ \text { \& migrations }}}{ }$}

\section{Hommes \& migrations}

Revue française de référence sur les dynamiques

migratoires

$1297 \mid 2012$

Migrations en création

\title{
Salah Guemriche, Alger la Blanche, Biographies d'une ville
}

Paris, Perrin, 2012, 415 pages, 24 euros

\section{Mustapha Harzoune}

\section{(2) OpenEdition}

Journals

Édition électronique

URL : http://journals.openedition.org/hommesmigrations/1566

DOI : 10.4000/hommesmigrations. 1566

ISSN : 2262-3353

Éditeur

Musée national de l'histoire de l'immigration

Édition imprimée

Date de publication : 1 mai 2012

Pagination : 169-170

ISSN : 1142-852X

Référence électronique

Mustapha Harzoune, "Salah Guemriche, Alger la Blanche, Biographies d'une ville », Hommes \& migrations [En ligne], 1297| 2012, mis en ligne le 29 mai 2013, consulté le 22 septembre 2020. URL : http://journals.openedition.org/hommesmigrations/1566; DOI : https://doi.org/10.4000/ hommesmigrations. 1566

Ce document a été généré automatiquement le 22 septembre 2020.

Tous droits réservés 


\title{
Salah Guemriche, Alger la Blanche, Biographies d'une ville
}

Paris, Perrin, 2012, 415 pages, 24 euros

\author{
Mustapha Harzoune
}

\section{RÉFÉRENCE}

Salah Guemriche, Alger la Blanche, Biographies d'une ville, Paris, Perrin, 2012, 415 pages, 24 euros

1 "El Bahdja, el Mahroussa, el Baïda : la splendide, la protégée, la blanche. Alger dans tous ses états. Sous l'occupation turque comme sous la colonisation française, dans sa résistance aux tortionnaires de Bigeard ou à la terreur islamiste, face à l'autisme de ses gouvernants ou aux calculs des spéculateurs immobiliers (qui, tels des vautours, guettent l'effondrement de la Casbah), Alger n'aura jamais perdu de sa 'candide blancheur."

2 Voilà pour le ton de ce livre dédié à la ville qui a vu grandir l'auteur et dont les rues, les lieux racontent le roman mouvementé et paradoxal de son peuple. Dans Alger la Blanche, les espaces et le temps s'enlacent constamment, densément et les (trop) nombreux chaos de l'histoire s'accrochent aux reliefs de son "intelligente" architecture façonnée par la nature ou par les hommes. Comme partout ailleurs, la misère y est sombre, mais ici le soleil "tue les questions", disait Camus dans Le Malentendu. Salah Guemriche est un journaliste intransigeant, à la plume alerte, souvent assassine, parfois subversive. Il ne donne ni dans les salamalecs, ni dans la danse du ventre. Il vit en France depuis bien longtemps et il est l'auteur de romans, de biographies et d'essais. Le ton, la curiosité et l'indépendance d'esprit rappellent un Péroncel-Hugoz. De ce point de vue et si l'on met de côté le fond, Alger la Blanche est à rapprocher de Villes du Sud (Balland, 1990) de l'ex-grand reporter du Monde. Pour donner à sentir et respirer "son" Alger, Salah Guemriche offre une "biographie éclatée" en 42 entrées qui déboulent tantôt sur une Alger "Sphinx-citadelle", longtemps terreur de la chrétienté, tantôt sur une 
Alger "ravissante", el Bahdja, la "belle à ravir". Si convoitée que ses fonds marins s'en souviennent encore qui conservent, emprisonnés depuis au moins le XVI siècle, quelques vestiges des armadas européennes, témoins des intentions chrétiennes partagées entre géopolitique, raisons domestiques et appétence pour le "trésor de la Casbah". Dans ce "parti pris" assumé, certains personnages, lieux ou événements prennent plus de place que d'autres. Ainsi, Boudjemaâ Kerèche alias "Boudj" l'infatigable, le courageux et ci-devant directeur de la cinémathèque qui fit du lieu "une université populaire pour tous". À l'heure où les salles de cinéma se comptent sur les doigts d'une main, Guemriche, qui à l'âge de toutes les promesses voulait tâter de la caméra, évoque longuement le $7^{\mathrm{e}}$ art. Du "fantasme colonial" au "fantasme nationaliste", la ville et ses habitants ont disparu des écrans. Pour les retrouver, il faudra attendre Tahia ya Didou de Mohamed Zinet, Omar Gatlato d'Omar Allouache ou Viva Ladjérie de Nadir Moknèche.

3 Non sans tendresse, Guemriche convoque Himoud Brahimi, alias Momo, "l'illuminé de la Casbah" le poète qui voit dans "sa" Casbah "la conscience endormie de la civilisation". Il se souvient d'Atahualpa Yupanqui. Et oui! C'était en 1969, au temps où le festival Panafricain célébrait la liberté des peuples, sauf pour les Berbères du cru. D’ailleurs, Taos Amrouche ne sera pas invitée, elle y viendra quand même, bravant les autorités et montrant aux jeunes venus l'écouter ce que le mot "nif" signifiait pour elle! Camus pourrait servir à illustrer un des nombreux paradoxes algériens : celui qui en prend le plus pour son grade est celui qui hante toutes les pages - et les consciences? - au point de figurer à 21 reprises dans l'index de fin, autant que "Bab-el-Oued". Seule l'entrée "Casbah" en remontre à ce Camus ici rudoyé avec assiduité, pour sa phrase sur le soleil "qui tue les questions", pour ne pas avoir été un Sénac, entendre un "indépendantiste" ou, une fois de plus, pour sa sortie sur sa mère et la justice... C'est pourtant le même Sénac qui écrira "j'ai vu ce pays se défaire avant même de s'être fait!". Quant aux rues d'Alger, Guemriche montre qu'elles se souviennent des 500 jeunes, des “indignés avant la lettre", écrit-il, assassinés en octobre 88. Il cite la terrible phrase d'Assia Djebar: “ Comment s'est faite la passation dans cette capitale du soleil, la passation entre tortionnaires."Dans l'Alger de Guemriche, on croise Karl Marx, Alphonse Daudet, Gide, les frères Goncourt (“conquis"), le très fidèle Saint-Saëns, Léo Ferré, Mohamed Racim le miniaturiste, Kateb Yacine ou un certain Ismaïl Aït Djafer et sa Complainte des mendiants arabes de la Casbah écrite en 1949. L'inestimable Mouloud Feraoun aussi, engagé pour le "sauvetage de l'enfance algérienne", dixit Germaine Tillion. Trente ans plus tard, un autre écrivain fera de l'école une priorité, Tahar Djaout. Il sera lui aussi assassiné.

4 La Casbah, patrimoine mondial de l'Unesco, a du souci à se faire. Après les "spéculateurs coloniaux", voici les "spéculateurs d'aujourd'hui et autres magnats du régime". Déjà, en leur temps, Saint-Saëns ou Delacroix s'indignaient des destructions (une "barbarie"!) opérées par les nouveaux maitres d'Alger. Ces destructions rendirent les colons bien peu fréquentables aux yeux de Napoléon III. Les saints tutélaires de la cité, à commencer par Sidi Abd er-Rahman, ne seront pas de trop pour veiller sur la ville. Guemriche y fait le tour des mosquées, des hammams et des fontaines, passe du Belcourt (Belouizdad) de Camus et de Cervantès à "Madame l'Afrique". Il traverse les cités "chaudes" construites entre 1954 et 1957 par Fernand Pouillon, les "pouillonades" selon l'humour de la rue algéroise, avant de flâner du côté de Ryadh El-Feth. Alger ne serait pas Alger sans le chaabi! Impossible de ne pas aller siroter un thé au café Le Tantonville ou au Malakoff, impossible de ne pas rendre hommage au maitre, le “ma'alem" Hadj M'Hamed El'Anka, et à tant d'autres. Ce genre musical montre 
qu'“Alger a toujours eu ses métis et ses 'sons mêlés”'. La diversité y est partout chez elle: "Entre sa souche berbère et son passé tour à tour judéo-berbère, phénicien, romain, vandale, byzantin, arabe, turc et français, Alger ne sait plus où donner de la mémoire." Pour que cet héritage ne soit pas un vulgaire "exotisme", il faudrait le laisser s'épanouir. Comme les femmes d'Alger. Elles sont là, debout aux heures sombres de l'histoire puis vite renvoyées à leurs “appartements", où elles s'adonneraient à quelques jeux divinatoires (la "boqala") conjecture l'auteur.

5 Fissa, on veut les claquemurer à double tour, comme ce 9juin 1984, jour de la promulgation du Code de la famille... Mais elles n'ont pas dit leur dernier mot et des surprises pourraient même venir d'un de ces nombreux clubs de football féminin. Le foot et Alger? Une autre passion. 